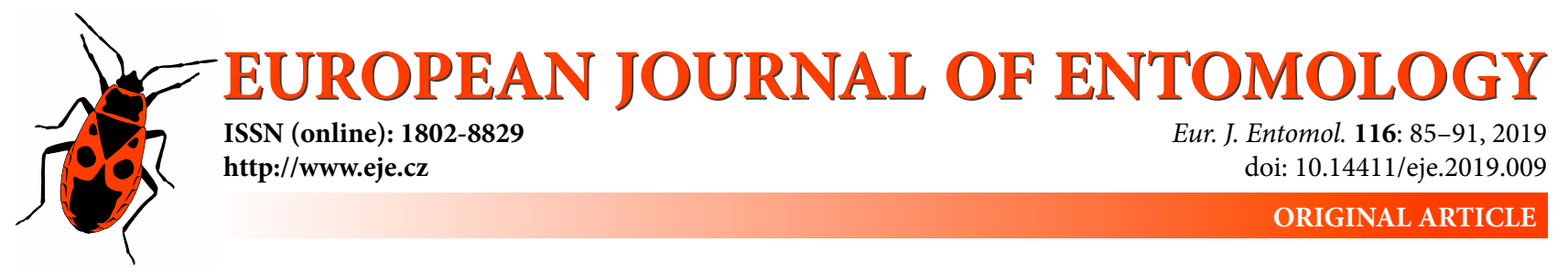

\title{
The effect of population density of Lymantria dispar (Lepidoptera: Erebidae) on its fitness, physiology and activation of the covert nucleopolyhedrovirus
}

\author{
Sergey V. PAVlushin ${ }^{1}$, Irina A. BelousoVA ${ }^{1,2}$, Ekaterina A. ChertKoVA ${ }^{1}$, Natalia A. KRYUKOVA ${ }^{1}$, \\ VIKTOR V. GLUPOV ${ }^{1}$ and VIATCHESLAV V. MARTEMYANOV ${ }^{1,3}$ \\ ${ }^{1}$ Institute of Systematics and Ecology of Animals, Siberian Branch of Russian Academy of Sciences, 11 Frunze Str., 630091 \\ Novosibirsk, Russia; e-mails: sergey-pavlushin@mail.ru, belousova_i@yahoo.com, chertkaterina@yandex.ru, \\ dragonfly6@yandex.ru, skif@eco.nsc.ru, martemyanov79@yahoo.com \\ ${ }^{2}$ Institute of Biology, Irkutsk State University, 1 Karla Marxa Str., 664003 Irkutsk, Russia \\ ${ }^{3}$ Biological Institute, National Research Tomsk State University, 36 Lenina Str., 634050 Tomsk, Russia
}

Key words. Lepidoptera, Erebidae, Lymantria dispar asiatica, baculovirus, covert infection, population density, insect physiology, fitness

\begin{abstract}
After high population densities of insect defoliators there is often a dramatic decrease in their abundance due to various limiting factors. Here, we compared gypsy moth larvae (Lymantria dispar L.) reared singly and in crowded conditions. We compared a number of physiological parameters of these insects and the effect of $L$. dispar population density on the activation of covert baculovirus infections in the larvae. It was found that the population density of gypsy moth larvae did not affect the mortality due to the activation of the covert virus infection or the total mortality. On the other hand, solitary-reared larvae were heavier, took longer to develop, and showed a four-fold higher concentration of dopamine in their haemolymph than larvae reared in groups. Thus, we demonstrated that an increase in the population density of larvae per se facilitates some changes in fitness and innate immunity traits but is not related to the activation of covert baculovirus infection. We suggest that an increase in population density does not increase the risk of epizootics triggered by the activation of covert baculovirus infection and that researchers should pay more attention to studying density-associated factors, such as starvation.
\end{abstract}

\section{INTRODUCTION}

The class Insecta includes species the populations of which fluctuate dramatically by as much as several orders of magnitude (Schowalter, 2006). Consequently, the role of density-dependent factors, such as predation/parasitism, in their population dynamics will differ significantly at different population densities (Myers, 1998). Usually, natural epizootics in insect herbivores are observed at high population densities because of the high probability of horizontal transmission (McCallum et al., 2001), and increased population density is considered to be one of the reasons for epizootics (Myers, 1998). On the other hand, some lepidopteran species, whose population densities are extremely variable, show so-called density-dependent prophylaxis, which increases host resistance against disease at high densities (Wilson \& Cotter, 2008).

In the current study, we investigated changes in performance and physiology of the widespread pest of forestry the gypsy moth Lymantria dispar L. (Lepidoptera: Erebidae), which are associated with high population density. $L$. dispar is a member of the spring feeding guild and regular outbreaks of this species occur in temperate forests in Eurasia, North America, Japan and north Africa. Previously, Reilly \& Hajek (2008) report that an increase in the population density of $L$. dispar larvae decreases its susceptibility to nucleopolyhedrovirus (NPV), even if the level of horizontal transmission of this disease is the same. There are sporadic studies on the physiology of $L$. dispar larvae reared under crowded conditions (Lazarević et al., 2004), but none on its innate immunity and changes in its resistance to pathogens. Studies on immunity in insects most often consider several of the following parameters to be predictors of insect resistance to many diseases, including viruses: components of cellular immunity, such as apoptosis, phagocytosis and encapsulation (Washburn et al., 1996; Trudeau et al., 2001; McNeil et al., 2010a), and components of humoral immunity, such as prophenoloxidaseactivating systems (Lee et al., 2006; Shelby \& Popham, 2006; McNeil et al., 2010a, b; Saejeng et al., 2010). Physiological processes such as apoptosis play an important role in the resistance to viruses (Hillyer, 2016), including baculoviruses (Clarke \& Clem, 2003; Clem, 2005; Yamada et 
al., 2012; Ikeda et al., 2013). For example, Ld652Y cells from the gypsy moth, L. dispar, undergo apoptosis upon infection with NPV, while the infection of Ld652Y cells with $L$. dispar MNPV ( $L d \mathrm{MNPV}$ ) results in productive infections, yielding higher titers of viral progeny (Ishikawa et al., 2003).

Under unfavourable conditions, the levels of octopamine and dopamine in the haemolymph and tissues of neural origin in various species of insects may increase dramatically (Gruntenko et al., 2005). This response is non-specific and is in response to stress, such as high or low temperatures and mechanical or chemical stimuli (Davenport \& Evans, 1984; Hirashima \& Eto, 1993; Rauschenbach et al., 1993). However, there are no studies on the levels of these biogenic amines in insects reared in crowded versus solitary conditions.

As mentioned above, some of the most lethal of viral pathogens occurring in insects (especially Lepidoptera) are baculoviruses (Cory \& Myers, 2003; Myers \& Cory, 2016). Often, viral disease reaches epizootic levels at peak host population densities. Some studies describe the relationship between host population density and the susceptibility of the host to baculovirus infection. For example, Kunimi \& Yamada (1990) show that when reared in groups, armyworm moths (Mythimna separata) are several times more resistant to baculovirus infection than insects reared under solitary conditions, that is, this moth exhibits density-dependent prophylaxis. Goulson \& Cory (1995) also show that caterpillars the cabbage moth (Mamestra brassicae) grown under solitary conditions are only weakly resistant to baculovirus. On the other hand, there is an increase in the susceptibility of $L$. dispar larvae to baculovirus infection at high population densities (Reilly \& Hajek, 2008). Most of the above mentioned studies, however, consider only the exogenous form of viral infection (i.e., peroral inoculation), whereas the interaction between hosts and the covert (asymptomatic) form of infection by vertical transmission from parent to offspring is poorly studied (Cory, 2015; Trevor et al., 2017). Despite the fact that many virologists state that covert infection is not important at the population level (reviewed in Kukan, 1999), recent studies indicate that the role of covert baculovirus infections and their activation in hosts affected by stress are underestimated (Burden et al., 2003; Sorrel et al., 2009; Vilaplana et al., 2010; Bakhvalov et al., 2012; Graham et al., 2012; Ilyinykh \& Polenogova, 2012; Martemyanov et al., 2015; Myers \& Cory, 2015; Trevor et al., 2017). Covert forms of baculoviruses can maintain low levels of replication within hosts without them showing any symptoms of disease (Hughes et al., 1997; Burden et al., 2003). When subjected to stress, however, this persistence may transform into an acute form of pathogenesis (Fuxa et al., 1999; Myers \& Cory, 2015). Thus, one of the aims of the current study is to reveal the role of host population density per se (i.e., in the absence of density-associated factors such as food limitation, host plant-induced resistance, etc.) in the transition of covert baculovirus infection into an overt infection.
Thus, this study addresses the question of whether population density affects herbivore performance, physiology and resistance to the covert form of baculovirus infection in an economically important forest defoliator, L. dispar.

\section{MATERIALS AND METHODS}

\section{Insects and experimental design}

This study was conducted using the gypsy moth, Lymantria dispar asiatica L. Approximately 100 egg masses were collected from a forest in the Novosibirsk region (western Siberia, Russia, $54.14^{\circ} \mathrm{N}, 79.71^{\circ} \mathrm{E}$ ) in autumn 2015 and kept in a refrigerator at $4^{\circ} \mathrm{C}$ (Martemyanov et al., 2015). The gypsy moth was at the peak of its population cycle in that year. Before the beginning of the experiments (at the end of diapause), all egg masses were cleaned of setae, homogeneously mixed, surface sterilized with sodium hypochlorite as described in Martemyanov et al. (2017) and then used as the stock for all experiments.

In the spring of 2016, all newly hatched first-instar larvae were kept under identical conditions: temperature of $+21^{\circ} \mathrm{C}$, relative humidity of $70 \%$ and under a natural daylight regime. During the first and second instars, all larvae were kept in a group (100 larvae per $20 \mathrm{~L}$ container) because young larvae normally aggregate on the host plant even at a low population density (Doane $\&$ McManus, 1981). In the third instar, the insects were divided into the following two groups: solitary-reared larvae (one larva per $1 \mathrm{~L}$ container, a total of 100 containers) mimicking the dispersion of middle-instar larvae in nature, and group-reared larvae (10 larvae per $1 \mathrm{~L}$ container, a total of 10 containers). The 10-larvae groups were chosen to mimic (under laboratory conditions) the peak population density of $L$. dispar in nature (more than 10,000 individuals per mature tree, personal observation, Fig. 1). As much higher densities may result in food limitation/ starvation, the number of larvae reared in groups was limited to 10. All larvae were fed cut birch leaves placed in $1.5 \mathrm{ml}$ tubes filled with water and sealed with Parafilm to maintain cell turgor in the detached leaves (Martemyanov et al., 2015). Larvae were reared in $1 \mathrm{~L}$ plastic containers that were covered with gauze for better ventilation. The leaves were preliminarily surface-washed using distilled water to prevent contamination by exogenous viruses (Martemyanov et al., 2015). If larvae died the container and leaves were immediately replaced. The leaves were changed daily and the quantity provided was sufficient to prevent starvation in the high-density treatment.

\section{L. dispar fitness}

The following fitness parameters of the single and group reared larvae were recorded: pupal weight of males and females (potential fecundity), duration of the larval stage, total mortality up to the adult stage and mortality induced by the activated covert nucleopolyhedrovirus. The procedures used to record the larval development stages and identify sex are described in Martemyanov et al. (2012). The etiology of larval mortality was identified using an Axioscop 40 light microscope (Carl Zeiss, Germany), as polyhedral inclusion bodies are optically visible. One hundred larvae per treatment were used to assess the life history traits in accordance with the experimental design described in the previous paragraph.

\section{L. dispar physiology}

Physiological parameters were estimated for fifth-instar larvae (12 days after the division into groups of different densities). For this study, other individuals were reared in the same way as described above. In total, one hundred larvae per treatment were used. Larvae was chosen at random from the container each 


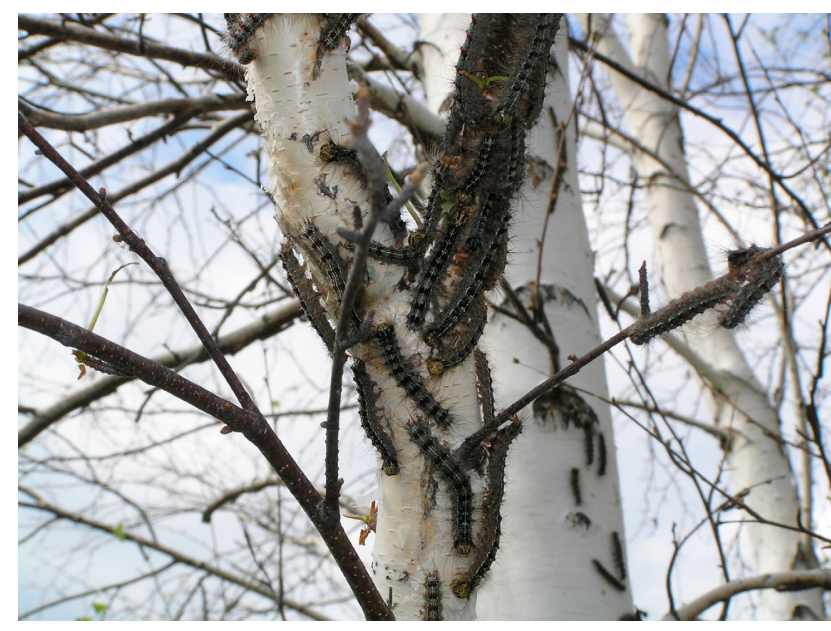

Fig. 1. Photograph of defoliated birch trees during the outbreaks of Lymantria dispar asiatica L. in nature (Russia, Novosibirsk region).

time. The following physiological parameters were measured: phenoloxidase (PO) activity in the haemolymph plasma $(\mathrm{N}=20$, for each group), total number of haemocytes (THCs) $(\mathrm{N}=20$, for each group) and number of apoptotic haemocytes $(\mathrm{N}=5$, for each group). In addition, because covert virus infections usually transform into an overt form when the host is under stress, we also estimated the concentration of dopamine in the haemolymph ( $\mathrm{N}=20$, for each group). Dopamine is a biogenic amine and an important component of the adaptive reaction to neuroendocrine stress in insects (Gruntenko et al., 2004).

The PO activity was determined spectrophotometrically using L-dopa as the substrate according to the method described by Martemyanov et al. (2012). Ten $\mu$ l of the supernatant was mixed with $500 \mu$ of L-dopa in phosphate buffer with a pH of 7.2 (solution concentration of $2 \mathrm{mg} / \mathrm{ml}$ ). After incubation for $40 \mathrm{~min}$ at $28^{\circ} \mathrm{C}$, the PO activity was measured at $490 \mathrm{~nm}$ using a PowerWave HT (BioTek, USA) UV-visible spectroscopy system. The duration of incubation was chosen based on the area under the initial linear increase in the activity curve obtained in a pilot study using insects from the same population for which the kinetics of enzyme activity were recorded. The final PO activity is presented as the difference between the absorbencies of the control and haemolymph samples per $1 \mathrm{~min}$ and $1 \mathrm{mg}$ of protein. The concentration of protein in haemolymph was measured using the process outlined by Bradford (1976) using bovine serum albumin as the standard.

Total haemocyte counts (THC) were done immediately after collecting the haemolymph using an Axioscop 40 light microscope (Carl Zeiss, Germany). To collect the haemolymph, each caterpillar was pierced with a thin needle. Then, approximately $25-30 \mu 1$ of haemolymph was withdrawn, with each sample being split equally into two Eppendorf tubes that were previously cooled to $4^{\circ} \mathrm{C}$. Part of the haemolymph from one tube $(4.5 \mu \mathrm{l})$ was mixed with $20 \mu \mathrm{l}$ of cooled anticoagulant with phenylthiourea for a THC. THCs were immediately made using a haemocytometer to quantify the number of haemocytes per $1 \mathrm{ml}$ of haemolymph (Martemyanov et al., 2012). The results are presented as the number of haemocytes per $1 \mathrm{ml}$ of haemolymph.

The concentration of dopamine in the haemolymph was measured using high-performance liquid chromatography (1200 series, Agilent Technologies, USA) coupled with a Coulochem III electrochemical detector (ESA) as described by Gruntenko (2005), with some modifications. During sample preparation, $40 \mu \mathrm{l}$ of larval haemolymph was collected. The ratio of perchlo- ric acid $\left(0.2 \mathrm{M} \mathrm{HClO}_{4}\right)$ to haemolymph in the samples was $1: 1$. After collection, the samples were incubated in a Thermo Biosan TS 100 at $28^{\circ} \mathrm{C}$ and $600 \mathrm{rpm}$ for $10 \mathrm{~min}$. The measurements were performed using an Agilent 1260 Infinity chromatograph with a ZorbaxSB-C18 reverse-phase column $(4.6 \mathrm{~mm} \times 250 \mathrm{~mm}, 5 \mu \mathrm{m}$ particle diameter). An ESA Coulochem III 5010A electrochemical detector with a cell potential of $300 \mathrm{mV}$ was also used. Chromatography using a 10\% acetonitrile system, $90 \% 26 \mathrm{mM}$ buffer (1-octanesulfonic acid, $\mathrm{KH}_{2} \mathrm{PO}_{4}$ ), a temperature of $27^{\circ} \mathrm{C}$ and a flow rate of $1 \mathrm{ml} / \mathrm{min}$ was used. The sample analysis time was 25 $\mathrm{min}$, and the volume of the sample was $10 \mathrm{ml}$. Dopamine hydrochloride (Sigma-Aldrich) at a concentration of $5 \mu \mathrm{g} / \mathrm{ml}$ was used as a standard.

The number of apoptotic haemocytes was estimated using an Annexin V FITC Apoptosis Detection Kit and calculated according to the manufacturer's protocol (Sigma-Aldrich, APOAF20TST). The haemolymph was collected from each caterpillar using a thin needle as described for THC. Then, approximately 25-30 $\mu 1$ of haemolymph was withdrawn and mixed with anticoagulant $\mathrm{pH} 4.5(62 \mathrm{mM} \mathrm{NaCl}, 100 \mathrm{mM}$ glucose, $10 \mathrm{mM}$ EDTA, $30 \mathrm{MM} \mathrm{Na}_{3} \mathrm{C}_{6} \mathrm{H}_{5} \mathrm{O}_{7}, 26 \mathrm{mM}$ citric acid) in a ratio $1: 10$. Then samples were washed 3 times by centrifugation $(500 \mathrm{~g} / 5 \mathrm{~min})$ and mixed with HEPES buffer $\mathrm{pH} 7.2$ (for $100 \mathrm{ml}$ volume: $800 \mathrm{mg}$ $\mathrm{NaCl}, 37 \mathrm{mg} \mathrm{KCl}, 240 \mathrm{mg}$ HEPES, $108 \mathrm{mg}$ glucose, $\mathrm{NaOH}$ for $7.2 \mathrm{pH}$ ). After repeated washing samples was resuspended in 80 $\mu 1$ of HEPES buffer and used according to the manufacturer's protocol. HEPS buffer preserves the cells for about $1 \mathrm{~h}$. Cell mortality was lower than $10 \%$.

\section{Estimation of covert baculovirus infections}

The prevalence of covert baculovirus infections in L. dispar was estimated using PCR. Ten samples of $L$. dispar eggs containing 10 eggs each (i.e., 100 eggs) were randomly chosen from the stock of egg masses for PCR analysis. As all samples were virus-positive, we used 20 additional samples of single eggs to increase the resolution of the estimate of prevalence. Moreover, to estimate the presence of virus in larvae, 10 additional samples from individual late-instar larvae (taken from the fat body) were also used. In total, 40 samples (10 pooled and 30 individual) were used to estimate the prevalence of baculovirus infection. Total DNA was extracted using the phenol-chloroform method (Castro et al., 2009), with some modifications. Egg masses were analyzed and mechanically homogenized in a lysis solution containing guanidine thiocyanate using pestles. For the late-instar larvae, the whole larval body (except for the gut and its contents, which were excised) was used as the source of the DNA. Before the extraction, the larvae were freeze-dried and then mechanically homogenized as described above. A control for successful DNA extraction was established by analyzing the Lymantria dispar L. 28S rRNA gene using PCR (Martemyanov et al., 2014).

A fragment of the polyhedrin gene (160 bp) was used as the target sequence for detecting the presence of $L d \mathrm{MNPV}$ DNA in the samples. The amplification reactions for the analysis of the gypsy moth NPV polyhedrin gene contained primer 1 at $50 \mathrm{nM}$, primer 2 at $50 \mathrm{nM}, 500 \mathrm{ng} / 25 \mu \mathrm{DNA}$ of the final volume, and the HS-qPCR Mix SYBR reaction mixture (Biolabmix). The reaction conditions were $5 \mathrm{~min}$ at $95^{\circ} \mathrm{C}, 30 \mathrm{~s}$ at $95^{\circ} \mathrm{C}$, and $1 \mathrm{~min}$ at $60^{\circ} \mathrm{C}$ for 40 cycles, with a melting curve of $60-95^{\circ} \mathrm{C}$. The primers for the gypsy moth NPV polyhedrin gene were GCACTTCCTCAACTCGGTCA and CGTTTAGTACGCCGGTCCTT (Primer-BLAST). Viral DNA detection was performed using SYBR Green on CFX96 (Bio-Rad). It should be noted that the use of this qualitative detection method lowers the limit of DNA detection in comparison to classical detection with ethidium bromide. DNA extracted from the eggs and larvae of the gypsy moth population 
that was free of $L d \mathrm{MNPV}$ was used as the negative control. The products of the PCR reaction were sequenced to confirm the presence of the target sequence.

\section{Statistical analysis}

Most of the data were normally distributed (assessed using the Kolmogorov-Smirnov test). Therefore, we performed a one-way ANOVA with treatment (density) as the fixed factor (Statistica 7.0). We used the mean values of the pupal weight and larval development for each container as one replicate for the groupreared larvae. Thus, $\mathrm{N}=10$ for those data. To avoid pseudo replication, the pupal weights and larval development times for the solitary-reared larvae were assigned to ten artificial replicates, and each replicate was calculated as the average of ten values. Thus, we used 10 replicates for the solitary insect data and 10 replicates for the group-reared insect data in the comparison using ANOVA. For the physiological data, we used one larva reared in an individual container (either under solitary or crowded conditions) as a replicate. The data that were not normally distributed (THC, PO, dopamine concentration) were log transformed before the statistical analyses. The percentage mortality and apoptosis activity were compared using the chi-square method.

\section{RESULTS}

\section{Mortality and prevalence of covert infection}

The PCR analysis revealed that all the larvae of $L$. dispar asiatica studied were infected with baculovirus. Both the total percentage mortality (i.e., including nonspecific sources of mortality) and virus-specific mortality induced by an activated covert infection were similar for insects reared under crowded and solitary conditions (total percentage mortality $=4 \%$ for group-reared larvae and $5 \%$ for solitary-reared larvae, $\chi^{2}=0.12, p=0.733$; virus-specific percentage mortality $=4 \%$ for group-reared larvae and $4 \%$ for solitary-reared larvae, $\left.\chi^{2}=0, p=1\right)$. The maximum ability of this $L$. dispar population to activate covert infection (induced by starvation) was estimated in terms of the $\%$ of larvae killed by the virus.

\section{Comparison of fitness parameters}

Solitary-reared insects took longer to complete their development and were heavier than group-reared insects (Fig. 2a, b). These differences were similar for both sexes (Fig. 2a, b).

\section{Comparison of physiological parameters}

The THC for the singly reared insects was lower than that for the group-reared larvae (Fig. 3a), while both the PO activity and protein concentration in the haemolymph did not differ (PO activity was $0.266 \pm 0.05 \Delta \mathrm{A}_{495} / \mathrm{min} /$ $\mathrm{mg}$ for singly reared larvae and $0.266 \pm 0.05 \Delta \mathrm{A}_{495} / \mathrm{min} /$ $\mathrm{mg}$ for group-reared larvae, $\mathrm{F}_{1,38}=0.123, \mathrm{p}=0.727$; protein concentration in the haemolymph was $4.29 \pm 0.63 \mathrm{mg} / \mathrm{ml}$ for singly reared larvae and $4.70 \pm 0.86 \mathrm{mg} / \mathrm{ml}$ for groupreared larvae, $\left.F_{1,36}=0.761, p=0.388\right)$. However, the singly reared insects had an approximately four-fold greater concentration of dopamine in their haemolymph $(0,022 \pm$ $0.007 \mathrm{ng} / \mathrm{mkl}$ for singly reared larvae and $0,005 \pm 0.004$ $\mathrm{ng} / \mathrm{mkl}$ for group-reared larvae, $\mathrm{F}_{1,38}=22.498, \mathrm{P}<0.001$ ) (Fig. 3b). The percentage of apoptotic haemocytes did not differ significantly in the two treatments.

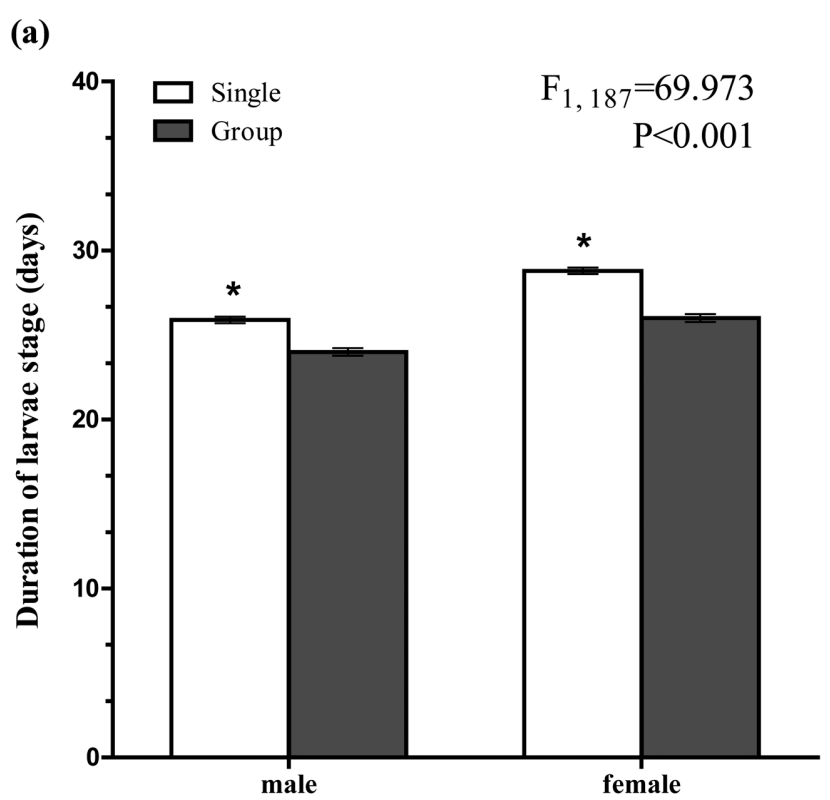

(b)

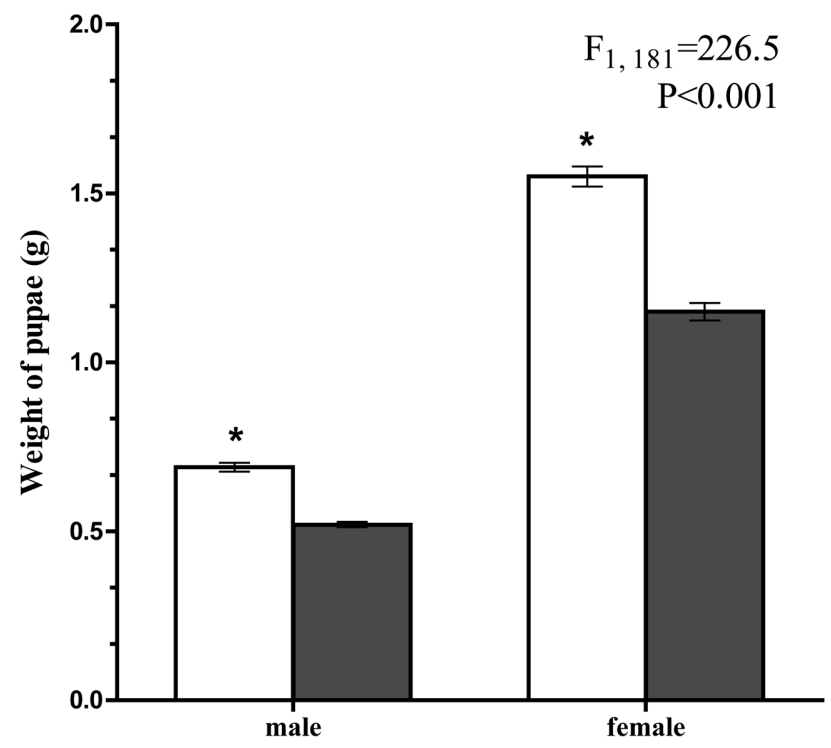

Fig. 2. Duration of larval development (a) and weight of pupae (b) when larvae are reared solitarily and in groups (mean \pm SE). Bars marked with asterisks indicate a significant difference (analysis of variance: Fisher's LSD test, $\mathrm{P}<0.05$ ).

\section{DISCUSSION}

This study shows that high population density per se of a host insect (L. dispar) did not affect its percentage mortality. It is interesting to note that solitary-reared larvae took longer to complete their development and were heavier. In another study, the mass of $L$. dispar larvae reared on an artificial diet is less when reared at a high population density (Reilly \& Hajek, 2008). A lower mass of crowded larvae is the usual response of insects that develop fast when crowded and occurs in other species of Lepidoptera (Goulson \& Cory, 1995), Orthoptera (Uvarov, 1966) and Coleoptera (Humiro et al., 2018). Heavy female pupae usually produce more productive adults, especially in species in which the adults do not feed (Honek, 1993), which is con- 
(a)

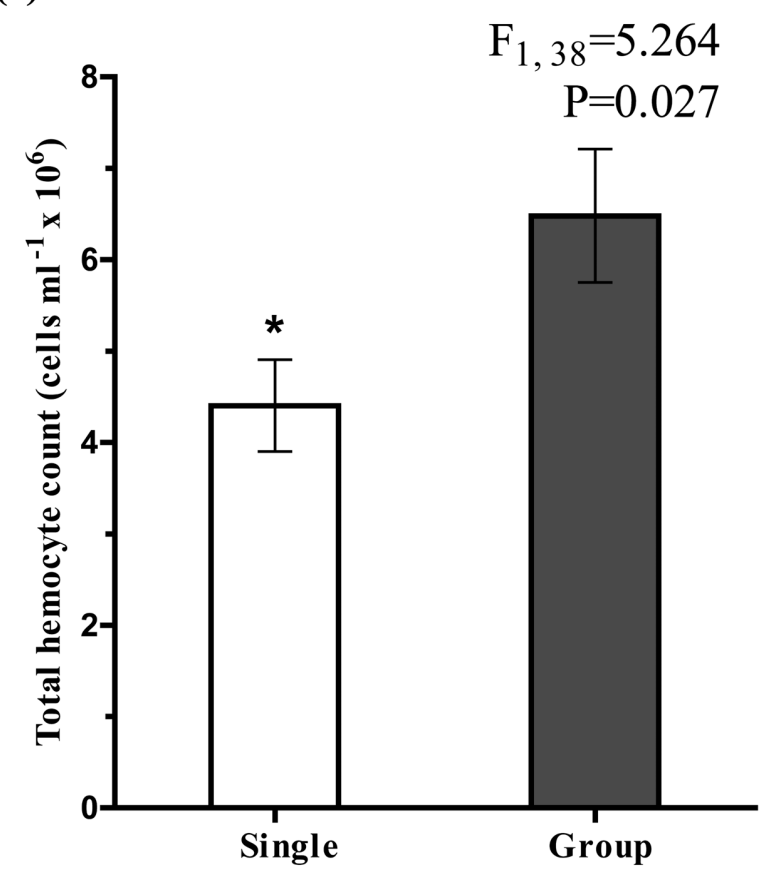

(b)

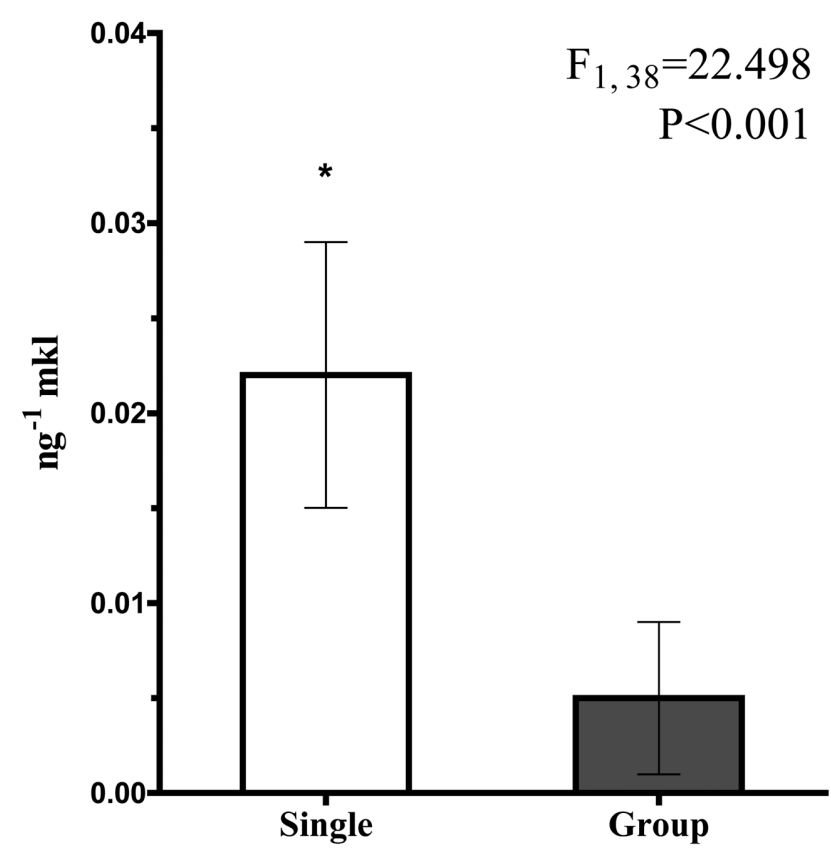

Fig. 3. Total number of haemocytes (a) and (b) dopamine concentration in the haemolymph when the larvae are reared solitarily and in groups (mean $\pm \mathrm{SE}$ ). Bars marked with asterisks indicate a significant difference (analysis of variance: Fisher's LSD test, P $<0.05)$.

firmed for other species of Lepidoptera (Miller, 2005). On the other hand, larvae with long development periods are more vulnerable to pathogens and parasitoids because of the increased window of opportunity (Doane $\&$ McManus, 1981). Our earlier study indicate that even at low natural population densities, L. dispar larvae are strongly affected by parasitoid pressure (Martemyanov et al., 2013). In ad- dition, a long larval stage increases the chance of a viral infection becoming activated.

We recorded an increase in the total number of haemocytes in the haemolymph of larvae reared under crowded conditions. This observation could be associated with the so-called density-dependent prophylaxis phenomenon (Wilson \& Cotter, 2008). However, density-dependent prophylaxis is not the case if we consider peroral baculovirus infection as the initiator of lethal disease in $L$. dispar. In particular, the stress caused by rearing $L$. dispar under crowded conditions leads to an increase in their susceptibility to peroral infection with baculoviruses (Reilly \& Hajek, 2008). This contradiction may be associated with the insignificant role of the THC parameter in the resistance of $L$. dispar larvae to nucleopolyhedroviruses (McNeil et al., 2010a, b). On the other hand, high THCs in the haemolymph of crowded larvae may account for the high resistance of larvae to other types of parasites (Lavine \& Strand, 2002; Tan et al., 2013).

Interestingly, the activity of PO in the haemolymph did not differ between the crowded and solitary larvae. This result indicates that the responses of different innate immunity parameters of insects (i.e., THC vs PO) differ in their response to the same factor. Thus, not all parameters of innate immunity are associated with density-dependent prophylaxis. Recently, we studied the effect of such density-associated factors, such as starvation, on the activity of $\mathrm{PO}$ in the haemolymph and found a significant increase in $\mathrm{PO}$ activity in the haemolymph of starved larvae (Kasianov et al., 2017). Thus, parameters of humoral innate immunity, such as the PO activity in haemolymph, depend on densityassociated factors, but not on the population density per se.

Dopamine is the primary indicator of stress in insects (Gruntenko, 2005). The four-fold increase in the dopamine concentration in the haemolymph of solitary larvae recorded in this study may indicate that solitary conditions are more stressful for both middle and late larval instars of $L$. dispar than crowded conditions.

We show that a high population density of $L$. dispar per se did not activate a covert form of baculovirus, but was associated with the absence of differences in important antiviral defenses, such as apoptosis. A previous study by Vilaplana et al. (2008) shows that high densities affect the vertical transmission of baculoviruses and prevalence of virus in the offspring of Spodoptera exempta. However, it is difficult to compare that study with ours because $S$. exempta has two phenotypically different forms, solitary and crowded (Rose et al., 2000), which have significant morphological, ecological and physiological differences (Applebaum \& Heifetz, 1999) and clearly demonstrate density-dependent prophylaxis against disease caused by baculoviruses (Vilaplana et al., 2008). L. dispar does not have a phenotypically distinct gregarious form (Doane \& McManus, 1981) or demonstrate density-dependent prophylaxis against peroral infection by $L d$ MNPV (Reilly \& Hajek, 2008).

The results of the present study clearly indicate that an increase in host population density alone is associated with 
fitness and physiological changes, but does not play a key role in the emergence of baculovirus epizootics in L. dispar populations driven by the activation of covert pathogens. Epizootics in insects (including L. dispar) usually occur at high population densities, but it would appear that the activation of covert virus infections does not directly relate to density but with associated density-dependent factors (such as starvation) that induce changes in the host. The roles of these factors in the appearance of epizootics due to the activation of covert infections should be further studied. On the other hand, our study shows that solitary L. dispar larvae invest more in growth, such as pupal mass, which leads to an increase in the number of progeny and, under favourable conditions, can result in an increase in population density.

In other words, less contact between middle and late instar larvae initiates an increase in the biotic potential of the population. This interesting phenomenon could be the basis for further studies on the mechanisms regulating insect population densities.

ACKNOWLEDGEMENTS. We would like to thank the director of the Karasuk Research Station, V. Shilo, for his help in the organization of the field work. This study was financially supported by the Russian Foundation for Basic Research (grant no. 15-04-08197) and the Federal Fundamental Scientific Research Program for 2013-2020 [(I.51.1.7. (0311-2016-0007), (AAAA-A16-116121410123-1)] and partially by the Russian Science Foundation (grant no. 17-46-07002) for the measurement of the prevalence of covert baculovirus infection in gypsy moth.

\section{REFERENCES}

ANDERSON R.M. \& MAY R.M. 1981: The population dynamics of microparasites and their invertebrate hosts. - Phil. Trans. R. Soc. Lond. (B) 291: 451-524.

Applebaum S.W. \& Heifetz Y. 1999: Density-dependent physiological phase in insects. - Annu. Rev. Entomol. 44: 317-341.

Bakhvalov S.A., Martemyanov V.V., Bakhvalova V.N. \& MoROzova O.V. 2012: Detection of the nuclear polyhedrosis virus DNA in samples from eggs and caterpillars at different stages of the gypsy moth Lymantria dispar (L.) population dynamics. - Vopr. Virusol. 57(4): 35-37.

BRADFORD M.M. 1976: A rapid and sensitive method for the quantitation of microgram quantities of protein utilizing the principle of protein-dye binding. - Analyt. Biochem. 72: 248-254.

Burden J.P., Nixon C.P., Hodgkinson A.E., Possee R.D., Sait S.M., KING L.A. \& HAILS R.S. 2003: Covert infections as a mechanism for long-term persistence of baculoviruses. Ecol. Lett. 6: 524-531.

Castro M.E.B., Ribeiro Z.M.A., Santos A.C.B., Souza M.L., Machado E.B., Sousa N.J. \& Moscardi F. 2009: Identification of a new nucleopolyhedrovirus from naturally-infected Condylorrhiza vestigialis (Guenée) (Lepidoptera: Crambidae) larvae on poplar plantations in South Brazil. - J. Invertebr. Pathol. 102: $149-154$.

Clarke T.E. \& Clem R.J. 2003: Insect defenses against virus infection: the role of apoptosis. - Int. Rev. Immunol. 22: 401424.

Clem R.J. 2005: The role of apoptosis in defense against baculovirus infection in insects. - Curr. Top. Microbiol. Immunol. 289: 113-129.
CORY J.S. 2015: Insect virus transmission: different routes to persistence. - Curr. Opin. Insect Sci. 8: 130-135.

Cory J.S. \& Myers J.H. 2003: The ecology and evolution of insect baculoviruses. - Annu. Rev. Ecol. Evol. Syst. 34: 239-272.

DavenPort A.K. \& Evans P.D. 1984: Stress-induced changes in octopamine levels of insect haemolymph. - Insect Biochem. 14: $135-143$.

Doane C.C. \& McManus M.L. 1981: The Gypsy Moth: Research Toward Integrated Pest Management. For. Serv. Tech. Bull. 1584, U.S.D.A., Washington D.C., 757 pp.

FuXa J.R., Sun J.Z., WeidNer E.H. \& LAMotte L.R. 1999: Stressors and rearing diseases of Trichoplusia ni: Evidence of vertical transmission of NPV and CPV. - J. Invertebr. Pathol. 74: $149-155$.

Goulson D. \& CORY J.S. 1995: Responses of Mamestra brassicae (Lepidoptera, Noctuidae) to crowding - interactions with disease resistance, color phase and growth. - Oecologia 104: 416-423.

Graham R.I., Grzywacz D., Mushobozi W.L. \& Wilson K. 2012: Wolbachia in a major african crop pest increases susceptibility to viral disease rather than protects. - Ecol. Lett. 15: 9931000 .

Gruntenko N., Chentsova N.A., Bogomolova E.V., Karpova E.K., Glazko G.V., Faddeeva N.V., Monastirioti M. \& RaUSCHENBACH I.Y. 2004: The effect of mutations altering biogenic amine metabolism in Drosophila on viability and the response to environmental stresses. - Arch. Insect Biochem. Physiol. 55: 55-67.

Gruntenko N.E., Karpova E.K., Alekseev A.A., Chentsova N.A., Saprykina Z.V., Bownes M. \& Rauschenbach I.Y. 2005: Effects of dopamine on juvenile hormone metabolism and fitness in Drosophila virilis. - J. Insect Physiol. 51: 959-968.

HILLYER J.F. 2016: Insect immunology and hematopoiesis. Dev. Comp. Immunol. 58: 102-118.

Himuro C., Kumano N., Honma A., Ikegawa Y. \& Ohishi T. 2018 : Appropriate number of inoculated eggs for mass-rearing the West Indian sweet potato weevil, Euscepes postfasciatus (Coleoptera: Curculionidae). - Appl. Entomol. Zool. 53: 157-164.

Hirashima A. \& Eто M. 1993: Effect of stress on levels of octopamine, dopamine and serotonin in the American cockroach (Periplaneta americana L). - Comp. Biochem. Physiol. (C) 105: 279-284.

HONEK A. 1993: Intraspecific variation in body size and fecundity in insects - a general relationship. - Oikos 66: 483-492.

Hughes D.S., Possee R.D. \& King L.A. 1997: Evidence for the presence of a low-level, persistent baculovirus infection of $M a$ mestra brassicae insects. - J. Gen. Virol. 78: 1801-1805.

IKeda M., Yamada H., Hamajima R. \& Kobayashi M. 2013: Baculovirus genes modulating intracellular innate antiviral immunity of lepidopteran insect cells. - Virology 435: 1-13.

IlyinYkh A.V. \& Polenogova O.V. 2012: Demonstration of the remote effect of baculovirus vertical transmission, with gypsy moth Lymantria dispar L. (Lepidoptera, Lymantriidae) as an example. - Zh. Obshch. Biol. 73: 389-395.

Ishikawa H., Ikeda M., Yanagimoto K., Alves C.A.F., Katou Y., Lavina-Caoili B.A. \& Kobayashi M. 2003: Induction of apoptosis in an insect cell line, IPLB-Ld652Y, infected with nucleopolyhedroviruses. - J. Gen. Virol. 84: 705-714.

Kasianov N.S., Belousova I.A., Pavlushin S.V., Dubovskiy I.M., Podgwaite J.D., Martemyanov V.V. \& Bakhvalov S.A. 2017: The activity of phenoloxidase in haemolymph plasma is not a predictor of Lymantria dispar resistance to its baculovirus. — PLoS ONE 12(8): e0183940, 16 pp. 
KUKAN B. 1999: Vertical transmission of nucleopolyhedrovirus in insects. - J. Invertebr. Pathol. 74: 103-111.

Kunimi Y. \& Yamada E. 1990: Relationship of larval phase and susceptibility of the armyworm, Pseudaletia Separata Walker (Lepidoptera, Noctuidae) to a nuclear polyhedrosis virus and a granulosis virus. - Appl. Entomol. Zool. 25: 289-297.

LAVINE M.D. \& Strand M.R. 2002: Insect hemocytes and their role in immunity. - Insect Biochem. Mol. Biol. 32: 1295-1309.

Lazarevic J., Peric-Mataruga V., Vlahovic M., Mrdakovic M. \& CVetanovic D. 2004: Effects of rearing density on larval growth and activity of digestive enzymes in Lymantria dispar L. (Lepidoptera : Lymantriidae). - Folia Biol. (Krakow) 52: 105-112.

Lee K.P., Cory J.S., Wilson K., Raubenheimer D. \& Simpson S.J. 2006: Flexible diet choice offsets protein costs of pathogen resistance in a caterpillar. - Proc. R. Soc. (B) 273: 823-829.

Martemyanov V.V., Dubovskiy I.M., Rantala M.J., Salminen J.P., Belousova I.A., Pavlushin S.V., Bakhvalov S.A. \& GLupov V.V. 2012a: The effects of defoliation-induced delayed changes in silver birch foliar chemistry on gypsy moth fitness, immune response, and resistance to baculovirus infection. $-J$. Chem. Ecol. 38: 295-305.

Martemyanov V.V., Dubovskiy I.M., Belousova I.A., Pavlushin S.V., Domrachev D.V., Rantala M.J., Salminen J.P., BaKhVALOV S.A. \& GLUPOV V.V. 2012b: Rapid induced resistance of silver birch affects both innate immunity and performance of gypsy moths: the role of plant chemical defenses. - Arthropod. Plant Interact. 6: 507-518.

Martemyanov V.V., Iudina M.A., Belousova I.A., Bykov R.A. \& ILINSKY YU.YU. 2014: The screening of Wolbachia infection in gypsy moth (Lymantria dispar) populations in Siberia. - Euroasian Entomol. J. 13: 494-496.

Martemyanov V.V., Pavlushin S.V., Dubovskiy I.M., Yushkova Y.V., Morosov S.V., Chernyak E.I., Efimov V.M., RuUhola T. \& GLupov V.V. 2015: Asynchrony between host plant and insects-defoliator within a tritrophic system: The role of herbivore innate immunity. - PLOS ONE 10(6): e0130988, 19 pp.

Martemyanov V.V., Podghaite J.D., Belousova I.A., Pavlushin S.V., Slavicek J.M., Baturina O.A., Kabilov M.R. \& IlyINYKH A.V. 2017: A comparison of the adaptations of strains of Lymantria dispar multiple nucleopolyhedrovirus to hosts from spatially isolated populations. - J. Invertebr. Pathol. 146: $41-46$

McCallum H., Barlow N. \& Hone J. 2001: How should pathogen transmission be modelled? - Trends Ecol. Evol. 16: 295-300.

McNeil J., Cox-Foster D., Gardner M., SlaviceK J., Thiem S. \& Hoover K. 2010a: Pathogenesis of Lymantria dispar multiple nucleopolyhedrovirus in $L$. dispar and mechanisms of developmental resistance. - J. Gen. Virol. 91: 1590-1600.

McNeil J., Cox-Foster D., Slavicek J. \& Hoover K. 2010b: Contributions of immune responses to developmental resistance in Lymantria dispar challenged with baculovirus. - J. Insect Physiol. 56: 1167-1177.

MiLLER W.E. 2005: Extrinsic effects on fecundity-maternal weight relations in capital-breeding Lepidoptera. - J. Lepid. Soc. 59: 143-160.

MYers J.H. 1988: Can a general hypothesis explain populationcycles of forest Lepidoptera? - Adv. Ecol. Res. 18: 179-242.

Myers J.H. \& CoRY J.S. 2015: Ecology and evolution of pathogens in natural populations of Lepidoptera. - Evol. Appl. 9: 231-247.
Rauschenbach I.Y., Serova L.I., Timochina I.S., Chentsova N.A. \& Schumnaja L.V. 1993: Analysis of differences in dopamine content between 2 lines of Drosophila virilis in response to heat-stress. - J. Insect Physiol. 39: 761-767.

ReILly J.R. \& HaJEk A.E. 2008: Density-dependent resistance of the gypsy moth Lymantria dispar to it's nucleopolyhedrovirus, and the consequences for population dynamics. - Oecologia 154: 691-701.

Rose D.J.W., Dewhurst C.F. \& Page W.W. (eds) 2000: The African Armyworm Handbook. 2nd ed. Natural Resources Institute, Greenwich, 304 pp.

Saejeng A., Tidbury H., Siva-Jothy M.T. \& Boots M. 2010: Examining the relationship between hemolymph phenoloxidase and resistance to a DNA virus, Plodia interpunctella granulosis virus (PiGV). - J. Insect Physiol. 56: 1232-1236.

Schowalter T.D. 2006: Insect Ecology: An Ecosystem Approach. 2nd ed. Academic Press, Burlington, MA, pp. 157-159.

Shelby K.S. \& Popham H.J.R. 2006: Plasma phenoloxidase of the larval tobacco budworm, Heliothis virescens, is virucidal. $-J$. Insect Sci. 6(13): $12 \mathrm{pp.}$

Sorrell I., White A., Pedersen A.B., Hails R.S. \& Boots M. 2009: The evolution of covert, silent infection as a parasite strategy. - Proc. R. Soc. (B) 276: 2217-2226.

Tan J., Xu M., Zhang K., Wang X., Chen S., Li T., Xiang Z. \& CUI H. 2013: Characterization of hemocytes proliferation in larval silkworm, Bombyx mori. - J. Insect Physiol. 59: 595-603.

Trudeau D., Washburn J.O. \& Volkman L.E. 2001: Central role of hemocytes in Autographa californica M nucleopolyhedrovirus pathogenesis in Heliothis virescens and Helicoverpa zea. - J. Virol. 75: 996-1003.

Uvarov V.B. 1966: Grasshoppers and Locusts. Vol. 1. Cambridge Univ. Press., Cambridge, UK, 481 pp.

Vilaplana L., Redman E.M., Wilson K. \& Cory J.S. 2008: Density-related variation in vertical transmission of a virus in the African armyworm. - Oecologia 155: 237-246.

Vilaplana L., Wilson K., Redman E.M. \& CoRy J.S. 2010: Pathogen persistence in migratory insects: high levels of verticallytransmitted virus infection in field populations of the African armyworm. - Evol. Ecol. 24: 147-160.

WashbuRn J.O., KirKPATRICK B.A. \& VolKMAN L.E. 1996: Insect protection against viruses. - Nature 383: 767.

Williams T., Virto C., Murillo R. \& Caballero P. 2017: Covert infection of insects by baculoviruses. - Front. Microbiol. 8: $1337,13 \mathrm{pp}$.

WiLson K. \& Cotter S.C. 2009: Density-dependent prophylaxis in insects. In Ananthakrishnan T.N. \& Whitman T.W (eds): Phenotypic Plasticity of Insects:Mmechanisms and Consequences. Science Publ., Enfield, NH, pp. 381-420.

WiLson K. \& ReEson A.F. 1998: Density-dependent prophylaxis: Evidence from Lepidoptera-baculovirus interactions? - Ecol. Entomol. 23: 100-101.

Yamada H., Shibuya M., Kobayashi M. \& Ikeda M. 2012: Baculovirus Lymantria dispar multiple nucleopolyhedrovirus IAP2 and IAP3 do not suppress apoptosis, but trigger apoptosis of insect cells in a transient expression assay. - Virus Genes $\mathbf{4 5}$ : 370-379.

Received September 5, 2018; revised and accepted March 13, 2019 Published online March 28, 2019 